\title{
A Study to Determine the Impact of Management on Public Service Motivation in Public Sector Employees
}

\section{Daniel McClure*}

Private Sector Political Intelligence Manager and Adjunct Professor of American Government, USA

\begin{abstract}
The intentions of this project are to provide information on the developing concept of Public Service Motivation (PSM) in Public Employees, specifically academic advisors in higher education. Initially there will be a review of existing literature on public service motivation and academic advisement. Specific topics will include research on desired rewards, developmental factors of PSM, organizational effects on PSM, measurement of PSM, how PSM influences performance, and methods to impact PSM. With a review of the literature in consideration, a research study will follow. It will be specific to the relationship, if any, of PSM and Management.

The study examines twelve academic advisors with six different supervisors. Each advisor and supervisor were interviewed and their responses were collected to a pre-determined set of questions that identify their Public Service Motivation levels. That data was organized and compared with other responses to observe trends and factors that impact the PSM levels across advisors. The conclusion of the study was that management does have a significant impact on PSM levels in academic advisors. This is important as it suggest the need for additional training and development of supervisors to more successfully capture and utilize high PSM levels in public servants.
\end{abstract}

Keywords: Public service motivation; Public administration; Leadership; Supervision; Public employees

\section{Literature Review}

Motivating employees is of particular importance to managers who seek to maximize efficiency and output. However, in recent years much effort has been dedicated to discerning the differences in public and private sector employees, and more specific to this paper determining motivations that are unique to public arenas. Perry and Wise [1] presented information regarding this concept and labeled it public service motivation. Their theory supports the idea of what they call PSM, or public service motivation, and they define it as "an individual's predisposition to respond to motives grounded primarily or uniquely in public services" [2]. If PSM exists it will be an important concept for public managers to understand and embrace. By studying the influence of management on PSM, public managers can employ strategies that may allow them to make their operations more productive and "institution and organizations must be organized to recognize and to take advantage of such motivations" [1].

Perry and Wise in their introduction of their PSM theory explain that they believe there are 3 types of public motivations, rational, norm based, and affective. The rational approach to PSM is that an individual is rational and makes decisions to maximize his or her utility. Some of the reasons that Perry and Wise point out that may underlie rational motivation include a "commitment to a public program because of personal identification with the program, participation in the process of policy formation, and advocacy for a special interest" [1]. The concept that employees are motivated by their rational decision making process is clear to understand and understandable in its application, however the rational incentives do not explain all of human interactions and decisions.

Norm based motivation is another idea to explain individual actions in the workplace. Perry and Wise point out that this idea may explain many decisions and motivations. The idea is that social norms have instilled certain ideals that will impact individual behavior. Some of these ideals include "a desire to serve the public interest, and a loyalty to the government as a whole" [1]. Norm based decisions, impacting PSM, incorporate some sense of loyalty that influences individual behavior and underlying this idea is the values of social equity. The last type of motivation Perry and Wise mention is affective motivation. They explain that this type of motivation may be driven from a "commitment to a program from a genuine conviction about its social importance" [1]. The initial Perry and Wise study left much to be addressed in subsequent research. One idea is evident and makes further research crucial; by understanding the different types of motivations that impact public services, it is clear that the idea of managing the public and private sectors the same is not ideal since these individuals appear to have different types of motivations.

\section{Measuring PSM}

If PSM is to be a valuable tool to public managers, it must have the availability to be measured. Without a measurement technique, applying the ideas of PSM to practice would be difficult at best. Perry [2] introduced a measure for PSM. The problems with measuring PSM, Perry explains, include the difficulty of measuring subtle and abstract ideas, as well as the difficulty of designing a scale and questions that did not elicit socially desirable responses. Perry's PSM scale initially began by looking at 6 different subscales, or dimensions. The subscales were attraction to policy making, commitment to the public interest, social justice, civic duty, compassion, and self sacrifice. Each dimension has a set of corresponding questions to identify how the respondent feels towards that dimension. Using those questions the data is to be

*Corresponding author: Daniel McClure, Private Sector Political Intelligence Manager and Adjunct Professor of American Government, USA, E-mail: danielmcclurejr@gmail.com

Received July 26, 2014; Accepted December 31, 2014; Published January 05 , 2015

Citation: McClure D (2015) A Study to Determine the Impact of Management on Public Service Motivation in Public Sector Employees. Review Pub Administration Manag 3: 148. doi:10.4172/2315-7844.1000148

Copyright: () 2015 McClure D. This is an open-access article distributed under the terms of the Creative Commons Attribution License, which permits unrestricted use, distribution, and reproduction in any medium, provided the original author and source are credited. 
compiled and overall PSM is to be determined. Throughout the course of the evaluation Perry eliminated 2 dimensions, social justice and civic duty; Civic duty was combined with public interest as they are highly correlated. After the combined values were analyzed, social justice was correlated to public interest, and as a result were also combined. The study concluded that policy making, commitment to the public interest, compassion, and self sacrifice are all confirmed dimensions of PSM that can be used to evaluate PSM. Perry explains that the 4 dimension scale may be refined by eliminating the self sacrifice dimension and becoming a 3 dimension scale, and by doing so the PSM accuracy and scale would be relatively unchanged. Worth noting is Perry's opinion after concluding this study that "PSM is less complex than is originally thought in the literature" [2]. The study concluded that the 4 dimension PSM scale is very valid and reliable, and will be useful in measuring PSM for future research.

Coursey and Pandey [3] conducted research to follow up on Perry's idea that a 3 dimensional scale would be useful and as efficient as the 4 dimensional scale. They hypothesized they could modify the scale to a shortened, yet as efficient version. This would make the survey easier to conduct, while still having an instrument to measure PSM. Perry's PSM scale consisted of 4 dimensions, and 24 questions to identify PSM of respondents. Coursey and Pandey suggest a different scale, consisting of 3 models and 10 questions to identify PSM. Their findings suggest "strong support for a 3 dimension solution and 10 item scale. Almost all of the evidence of validity and reliability are equal or better than Perry's research" [3]. This 3 dimensional scale, in addition to Perry's 4 dimensional scale, provides another useful measure of PSM. Having a way to measure provides managers and researchers ways to use PSM in public administration. Both studies have provided measurement tools that make PSM research possible and quantifiable.

\section{Motivation and rewards in public service}

Public Managers have for some time disputed the idea of whether or not the public and private sectors should be managed in the same way. Many individuals have claimed to increase efficiency in the public sector more private sector solutions should be implemented. With the development of a PSM scale, information regarding worker motivation can be measured to identify motivators, needs, and differences. In regards to motivating employees to increase efficiency, it is important to understand the types of rewards that employee's desire. By embracing the reward needs for employees, managers can respond to those needs in a manner that extracts the greatest possible amount of worker motivation, and thus in turn increases the probability to increase performance. Philip Crewson [4] conducted research on the rewards structures desired 1 by public and private employees. In particular he was interested in evaluating of intrinsic and extrinsic rewards were desired by one group, public or private, and if each group preferred different reward types. The first hypothesis he was concerned with testing was "is there generalizable evidence that public-employee reward motivations differ from private-employee reward motivations?" Crewson looked at research on public and private sector employees, and determined that "whether a result of recruitment, self-selection, or socialization through cultural effects and reward structures, public sector employees are less likely to be interested in economic rewards than are private sector employees and more likely than are private sector employees to perceive intrinsic service rewards as important" [4]. Crewson concluded that these differences lie at the heart of differentiating the types of workers and the worker behavior. The reward motivations that drive each type of employee will impact how they perform, Crewson believes. Crewson states that there is an observable interaction of PSM and organizational commitment. As a result, as commitment increases there will be a greater likelihood that performance will increase. $\mathrm{He}$ explains this increase in performance is due to the likelihood that as commitment increases, employee turnover and absenteeism will decrease. He feels that both lower turnover and absenteeism will lead to higher levels of employee effort and performance.

Building upon the reward motivations of public employees is important in understanding how PSM may be harnessed to benefit organizations. Gregory Mann [5] researched and explored this topic in 2006. His researched consisted of surveying employees of not for profits, the federal government, and the private sector. He then compared the results and levels of PSM to determine if any trends exist. His conclusions were very useful in explaining worker motivations. One of the most striking examples is the responses to the questions regarding if respondents cite their paycheck as the reason they come to work. Of respondents, $16 \%$ of not for profits said paycheck was the reason, compared to $31 \%$ of the federal employees, and $44 \%$ of private sector employees. Additionally, Mann researched why employees took their jobs in the first place. $60 \%$ of not for profit workers joined to "help the public, not for job security", compared to $32 \%$ for the federal government, and $20 \%$ in the private sector. Also, when asked the question regarding why they joined the organization, if it was for "the chance to make a difference, not the salary and benefits", $61 \%$ of not for profit workers responded yes, compared to $27 \%$ of federal workers, and $22 \%$ of private sector employees.

Mann did not calculate PSM using Perry or Crewson's scales, but his questions and analysis does provide a very clear picture of the differences between the motivations of public and private sector employees. The motivating factors are not expressly explored by Mann, but having the understanding that the motivating factors of employees do differ, and at some levels differ significantly, opens up the possibility to further prove that managing all employees the same is very unwise. His study shows the diversity of motivating factors and that entering public service for many is a decision founded primarily in service rather than extrinsic reward structures.

Building upon Mann's study [5], Leonard Bright [6] attempted to understand what exactly motivating factors are for public employees, and if high PSM levels correlated to any desired reward motivations. His hypothesis was "that PSM would be correlated to the intrinsic, non-monetary preferences of public employees when no confounding relationships are taken into account". This hypothesis was confirmed in the study and PSM was found to be significantly related to the intrinsic non-monetary opportunities included in the study [6]. He tested 5 different elements that are motivating factors. All of the elements in the study were at minimum somewhat desired by public employees. The two most preferred were professional growth and task meaningfulness, followed by the others which were leadership responsibility, career advancement, and personal recognition all being somewhat desired. The study showed that individuals with higher levels of PSM desired personal recognition, task meaningfulness, leadership responsibility, and professional growth at higher rate than those who had lower levels of PSM. Also, PSM was negatively related to respondents choosing "career advancement" as a top motivating factor. The results of this study give strong supporting evidence that PSM is directly correlated to the motivating factors desired by employees. It also provides ideas as to what those motivating factors may be. This research does not explain causality between PSM and desired motivating factors.

It is strongly supported by the evidence that individuals who choose careers in the public sector are doing so by motivations that differ from 
other fields. What is not clear is why and how these decisions are made. However, Mann points out that since these individuals are motivated by intrinsic factors to a large degree, it's no wonder that "two decades worth of experimenting on pay for performance in the public sector have not paid off this far" [7]. Understanding this striking difference between the public and private sectors may prove helpful, Crewson points out that "a delicate balance must be achieved between providing adequate economic rewards and taking care not to destroy or ignore the intrinsic or service needs of public employees. This balancing of rewards in the public sector cannot rely solely on private sector assumptions or techniques" [6].

Boardman and Sundquist [7] conducted a recent study to address worker motivations in the public sector. They surveyed 518 public health and human services managers with 274 responding to the questionnaires. They were particularly interested in understanding public manager's perceptions towards how their work contributes to benefitting the public. The researchers hypothesize that three categories will impact the level of service a public manager provides to the public. Those categories are job satisfaction, role ambiguity, and organizational commitment. They hypothesize and support from previous literature that job satisfaction will impact motivation and performance of individuals. They use satisfaction as a dependent variable in their study. Additionally they study role ambiguity as a dependent variable. They define role ambiguity as a lack of clear understanding of responsibilities. Previous studies have found negative psychological outcomes as a result of role ambiguity that most importantly impacted satisfaction. They hypothesized that role ambiguity would negatively impact motivation levels. And finally they also analyzed organizational commitment in regards to how it impacted worker motivation and performance. Admittedly they report that measurement of commitment is difficult and could result in socially desirable outcomes, they feel that a study of normative and affective commitments would be useful to the study and will impact worker motivations as well.The results of their research are helpful and contribute a lot to the PSM community. They found that as a managers understanding of serving the public increases; their job satisfaction increases, role ambiguity decreases, and organizational commitment increases. These findings are helpful for PSM researchers and managers alike. All three variables have been shown to impact motivation and performance in individuals employed in public service.

\section{Antecedents to PSM}

In an effort to understand some driving factors of PSM Perry et al. [8] studied antecedents of PSM. They looked at both informal and informal volunteering based respondents, and identified if PSM was affected by family socialization, religious activity, volunteering, and youth volunteering. The formal and informal volunteering based model identified that family socialization, religious activity, and formal volunteering all had a statistically significant impact on PSM, with the highest being family socialization and religious activity. This research contributes to the growing literature on PSM and provides evidence that individuals with higher levels of PSM have a specific set of antecedent factors that lead to their behavior, and PSM. Individuals with high PSM may be a product of their developmental environment, or their passions drive them to serve; either way they are simply different types of people than those individuals who do not have high PSM and they should be managed differently.

\section{PSM and performance}

The relationship between PSM and performance is important to understand. As the ongoing debate continues regarding why individuals develop PSM, it is also important to understand how PSM and performance interact. Lewis and Alonso [9] used a condensed PSM scale to evaluate employee PSM and performance for Public employees. They did this by using surveys sent to Federal workers throughout the United States. "The U.S. Office of Personnel Management (OPM) sent its Survey of Federal Employees (SOFE91) to 56,767 employees and achieved a 54\% response rate. The U.S. Merit Systems Protection Board (MSPB) mailed its survey (MPS96) to 18,163 federal employees and got a response rate of 53\%" [7]. They then condensed their sample to white collar employees for a total of 35,000 employees. They found that individuals with higher levels of PSM had higher levels of performance than those with lower levels of PSM. Additionally, Brewer and Selden [10] investigated the relationship between PSM and whistle blowing. They concluded that individuals with higher levels of PSM were more likely to be involved with whistle blowing activities. Whistleblowers were employees who had high levels of performance and had high levels of achievement, job satisfaction, and job commitment. Having empirical evidence that employees with higher levels of PSM perform more effectively is yet another reason why understanding PSM and developing ways to employ and improve it is so important.

\section{Organizational Impacts on PSM}

In an effort to understand how to influence PSM Moynihan and Pandey [11] conducted research regarding Organizational Impacts on PSM. Their hypothesis include that different socio-historical, cultural, and organizational factors will impact PSM of employees. They surveyed individuals using Perry's PSM scale to determine PSM. The socio-historical factors they studied were education and professional identification. The cultural factors they identified for study were group culture, developmental culture, hierarchal culture, and rational culture. They then tested organizational factors which included the appearance of red tape in an organization, the reform orientation of the organization, the existence of a hierarchy authority, and the length of organizational membership. They also examined age, income, and gender.

Their findings were that the cultural factors they identified, as well as age and income did not have any statistical significance on PSM. The other two categories, socio-historical and organizational, did have a statistically significant influence on PSM. These findings were of special significance to managers as it shows that specific changes within their own organizations may motivate workers. The existence of red tape had a negative relationship with PSM. A reform orientation in the workplace and an existing hierarchical structure both had a positive impact on PSM. Disappointing to managers and researchers alike is the finding that the longer the individual has been a part of the organization the lower their PSM will be. This is due to several reasons; among them include organizational structure, burn out, and personal experiences. Management can combat this however by monitoring and correcting organizational flaws, hindrances, and eliminating discouraging policies. Another interesting finding is that individuals who are in a professional organization have higher levels of PSM than those that are not. Overall, these findings suggest that there are variables that can be identified to have a positive or negative relationship on PSM, and ideally by focusing on those factors strategies can be developed that may prove helpful to public management through increased performance and results.

\section{Personal characteristics and PSM}

Leonard Bright's [12] study on PSM looked into personal characteristics that might be indicators of the potential for an individual to have higher levels of PSM. His study consisted of surveying at 
random individuals in county government in Oregon. He surveyed 329 individuals from 12 different departments within the county. The backgrounds and occupations of the respondents were very diverse. The mixture also was a mixture of managers and non managers, men and women, and members of different ethnic and social classes. They had several different sets of findings. First, they observed that individuals who were non managers tended to have lower levels of PSM than those individuals who were managers. Additionally, they found Evidence to support the Perry and Wise hypothesis that individuals with higher levels of PSM were driven less by monetary rewards than those with lower levels of PSM. Other characteristics that they observed were that individuals with higher levels of PSM tended to be females, and have higher levels of educational attainment. They attribute this difference in PSM to the different societal experiences and expectations that occur regularly in today's society. They list as an example the fact that males are expected to be more dominant and controlling while females are more nurturing and accepting. Although Bright identifies traits that could be used to determine an increased likelihood of PSM to be present in a greater amount, he admits that a causal relationship cannot be explained. Additionally he suggests that highly motivated individuals in the private sector may share a large amount of qualities with those that are high PSM public workers.

\section{Entering public service}

Many articles to date have assumed that individuals enter into public service due to their greater levels of PSM compared to their private sector counterparts. Georgellis and Tabvuma [13] conducted a study to follow the movements of employees and to determine if individuals with differing levels of PSM entered public service for intrinsic or extrinsic rewards, and their satisfaction based on those transitions into different sectors and jobs. They used the British Household Panel Survey from 1991 to 2007. This consisted of approximately 10,000 individuals and 5,500 households per year. They used job satisfaction questions to determine the intrinsic and extrinsic rewards of the job transitions. The individuals transitioned into the public and private sectors and allow a good cross sectional analysis to be conducted. When individuals transitioned into a private sector job from a private sector job, data showed increased job satisfaction. However, that satisfaction only persists for one year and abruptly declines for all populations in the study. After the one year the remaining positive notes on satisfaction are purely extrinsic rewards. Intrinsic rewards decline significantly after the first year. The researchers concluded that the majority of the increase was related to the extrinsic rewards that exist in the field, but become outdated after the one year and are no longer sufficient to sustain satisfaction over the long term.

Individuals who entered into the public service fields showed increases in overall job satisfaction. That increases was sustained for at least five years. They observed an appreciation for intrinsic rewards for individuals entering into the public sector. They conclude that individuals who enter into the public service fields enjoy intrinsic rewards and as a result have higher levels of PSM than individuals who have entered into private sector fields. Their study was not on selection of careers but concentrated on results. The results derived from the assumption that for overall satisfaction intrinsic rewards can be more meaningful and can sustain themselves for longer periods of time. Additionally this study shows data that supports previous studies that PSM decreases over time. This provides additional needs of research to determine how to sustain PSM longer to gain more productivity and higher levels of performance out of employees over the long term. Clerki et al. published a study on determining factors of undergraduate students to engage in volunteering or donating activities in their communities. The researchers used data collected from surveys in an Introductory Political Science course at South Carolina State University in 2007. The sample was not random, but did however have a reflective sample of the university population for age, demographics, and other identifiable characteristics. They used the Perry Scale for measuring PSM. Their results concluded that students with higher levels of PSM were more likely to be engaged in volunteering and donating activities. Not all elements of the Perry PSM Scale were relevant to volunteerism; self sacrifice and attraction to public policy making were negatively correlated. The research provided two very important observations to PSM literature. First, individuals may have high levels of PSM but may not be high in all areas of the previous definition. This is important to understand and may prove to be an important point for subsequent research. And second, the finding that PSM does appear to be correlated to Volunteerism provides additional support for the claim that individuals with PSM do so because of a willingness and desire to help others.

\section{Manager-employee relationships}

Paarlberg and Lavigna [14] explain in their study that management research indicates that a value approach strengthens the manager employee relationship. When the manager works with the employee to explain their values and the values of the company the individual employee has higher levels of motivation. When employees understand the value systems of the manager they are able to internalize the manager values and combine them with their own to strengthen employee behavior and drive employee decision making. There are several studies that show this concept to be accurate, including Park Rainey [15]. This study looked at Federal Employees and their PSM levels. They concluded that as managers allowed individual employees do combine their values with the values of the task they had to perform and of the organization that PSM levels increased through empowerment.

However, managers who have good values cannot increase PSM levels of the subordinates if the employees to not understand those values or motivations. Grant and Sumanth [16] conducted a study addressing the manager-employee relationship. Through this study they make the conclusion that the perception of the employees is as important as the actions/motivations of the manager. The ability of the manager to impact the motivations of the employee are directly related to whether or not the manager can display and communicate effectively the values they find important, and whether or not the employee perceives those values accurately.

Wimbush and Shepard [17] also provide insight into how manager and employees interact. Their study focused on the conduct of employees and whether or not they adhered to institutional policy or not. Wimbush and Shepard suggest that managers and organization leaders are one of the largest driving factors in employee performance. They found that individual employees will make their decisions on how to observe and follow policy by how their manager respects and follows policy. They found that when managers openly broke policy the employees felt empowered to do the same, and when managers openly respected and followed policy the individual employees followed the policy as well. This being the case it is important for organizations to select managers that exhibit good values and that transcend individual self interest [18].

Paarlberg and Lavigna explain that through their study they have not found one "silver bullet" to build better employees. They explain 
that "silver buckshot" is the key and that through good management employees can be more committed and place more value in their task and the organization. Their conclusion is that "recruiting and hiring employees with strong public service values will only work if the recruits perceive that their tasks are important and that they work in environments that enable them to act on their motivations" [12]. There is a substantial amount of evidence to suggest that high levels of PSM are a helpful attribute in public employees. There is evidence that PSM is developed and caused through certain antecedent factors, as well as evidence that the workplace itself can foster or deter higher levels of PSM. The challenge in the future is to understand how managers can improve levels of PSM in employees. By doing so it can be reasonably assumed that performance will increase and can be sustained. Lewis and Frank address this issue by saying managers should seek desirable levels of PSM by "recruiting employees that are favorably predisposed to government service" and by doing so potentially improving performance.

\section{Advisement and PSM}

If PSM is able to be understood and influenced by managers, those tactics will also be helpful in Higher Education. Academic advisors are the ideal example of a public service motivated profession. They are responsible for helping students though their collegiate careers, and assist them with their problems. Academic Advisors are the first line of assistance for Higher Education students in course selection and degree progression. This role is similar in both the public and private sectors of Higher Education, as both areas primary roles are to assist students. In Higher Education there is a wide array of approaches to student service, and particularly academic advisement. Each advisor has a different approach and their understanding of their roles change from person to person and institution to institution. Michael Walsch explains the different roles and approaches that may be taken by Academic Advisors. Walsch points out that the primary role of Academic Advisors is to handle the bureaucratic operations of higher education. Typically this includes course selection, record keeping, and enrollment services for the students they serve. This role is important to the working of educational institutions, but can however be efficiently performed by individuals with lower levels of PSM. The reason for this is if all the work is completed, the advisor can be effective in their missions of enrolling, suggesting courses, and record keeping. Walsch suggest that the roles of academic advisor however cannot simply to be that of a bureaucrat. They must take on additional roles to best serve students. These roles include counselor, advocate, and guardian. The Counselor role of the Academic Advisor is to provide individualized assistance on problems facing the student. They should have training in counseling theory and approaches. They should provide guidance on individual issues, but should understand what issues should be referred for more professional and specific assistance. The next role is that of the Guardian. This role consists of "maintaining the integrity and quality of the degree". This consists of ensuring coursework that is preferred and recommended is at an appropriate level of difficulty and rigor. And the last role Walsch recommends is that of the advocate. This role places the advisor as an individual who directs students to services and programs on campus that will serve them and advance their academic and personal lives. Additionally the advocate role is to maintain a prostudent mentality, and handle situations on behalf of the student with other departments who may have different motivating factors ahead of the student's individual needs. Implementing the roles as suggested by Walsch would indicate a dedication towards serving students first (Public Service Motivation). In the situation where advisement staff implements these approaches to academic advisement in practice, it may indicate higher levels of PSM in the advisor/supervisor. There are various different approaches to academic advisement and some are more student centered than others. Some are simply transactional while other are more transformative (designed to help the student reach their highest level of success). By implementing the roles that Walsch suggests, a higher level of PSM would be being deployed which may result in higher levels of performance overall. Susan Dodge explains how some institutions are trying to change the way students are advised. She explains the fundamental problem with traditional academic advisement is that it is too "doctor-patient" like. Students come in whenever they have a problem and the advisor (doctor) simply writes them a prescription and they are on their way. This is very transactional and does not take enough effort to help in the transformation of the student's life. The approach she prefers is the faculty advisor approach. Many academic leaders feel it is useful to have faculty members who teach the courses also do the advising. They are subject matter experts and will be able to guide students to worthwhile courses and curriculum that will meet their individual needs. Dodge also expresses the idea that faculty advisors should mentor their students. As experts in their respective fields they can provide guidance and advice in and out of the classroom and this would build relationships that can last longer than the traditional advisement experience.

Another approach to providing quality advisement is explained by Kellie Bartlett in "Advise for Academic Advisors" published in the Chronicle for Higher Education [19]. She explains that being a great academic advisor goes beyond the traditional academic advisement mentality. She suggest that to better serve students advisors should get to know their student on paper before they get to know them in person. She outlines this process to include doing adequate research on the students past to give a better idea of how to serve them. This process is more than simply understanding their academic successes and failures. Some ideas that might be helpful include understanding the student's home life, extracurricular activities, and previous work history if possible.

Understanding the student's home life may give an indicator into their mentality towards higher education, and specific needs they may have. For example if that student is a first generation student they may be coming into the University with little or no knowledge of the higher education lifestyle or expectations that go along with it. They may be ill equipped mentally and a good advisor may explain to them in more detail certain aspects that may be foreign to the student. If the advisor looks at the students extracurricular and previous work histories, they may gain a better understanding of the student passions and be more prepared to recommend certain careers or majors. Essentially, she suggests, a little research can go a long way towards helping students. This effort is not required by the majority of higher educational institutions and its individual implementation would differentiate high vs. low PSM advisors.

\section{Summary}

Public Service Motivation is an interesting element inside the hearts and minds of public servants. PSM is instilled into individuals before they seek to work in the public sector. They are often times predisposed to have higher levels of PSM. This is often due to their experiences at an early age, as well as their individual passions that drive them. Additionally it is understood and supported through existing and previous studies that public employees seek different levels and types of rewards than private sector employees. This distinction is important to understand and can be used by employers to better work with their employees. Understanding PSM is important to managers 
as employees who have higher levels of PSM are likely to perform better. The task for management is to understand how to harness and keep PSM high. It is recommended by the literature that PSM is not something that managers will build or instill in an employee, they will usually be predisposed to have it or not. Managers can however understand PSM and how to keep it and maintain it in their employees, as well as recruit employees who have high levels of PSM. Additionally it is believed that by developing a workplace that allows individuals who have had high levels of PSM in the past the opportunity to revert back and increase their PSM under the appropriate circumstances. It has been established that different factors in the workplace can deter or decrease levels of PSM in employees. Understanding these factors can contribute to the sustainability of PSM and it is hoped to increases in performance as well.

\section{Research Design}

Different levels of PSM in the workplace have different impacts on employees. As indicated by supporting literature, higher levels of PSM result in higher levels of effort and performance. Also following the assumption that individuals who choose careers in public service are often predisposed to have higher levels of PSM, efforts to increase and maintain PSM will be beneficial to public service employers. Understanding that PSM can be impacted by different factors, it will be beneficial to understand specifically how manager behavior impacts PSM.

Studying PSM in Academic Advisors will be a good lens through which PSM and its interaction with management can be understood. Academic Advisors are truly a service oriented job. Their attitude and motivations will potentially impact the lives of students forever. It is not rare for the interaction between student and advisor to change a student's life and many situations have been documented both positive and negative. A study of PSM, advisement, and management is an important case study relevant to the public management/ administration community. This PSM study will shed light on whether or not managers can impact PSM directly in their subordinates through their management styles, behavior, and outlook on education. This is important to the management community because if managers in the public sector can in fact impact the PSM levels of their employees, additional research can be done to determine in what way this could occur. This may contribute to the increased level of PSM in employees in public service sectors and potentially contribute to greater service, performance, and efficiency.

This study will be to identify if management approaches by Advisement supervisors can directly increase the quality of student outcomes. It is assumed that academic advisors are predisposed to have higher levels of PSM and choose to become academic advisors to serve and help students. This is assumed due to Perry's explanation of the existence of PSM. The existence and reasoning for differing levels of PSM from one individual to another is not the concentration of this study, nor is it being questioned. The underlying principle is that Public Servants, in this case Academic Advisors, have or have had higher levels of PSM compared to non public service individuals. Moynihan and Pandey [20] showed that organizational impacts can impact the levels of PSM in Public Service employees. This study will follow up on those findings in an effort to determine other ways PSM may be affected. The hypothesis here is that management will have a significant effect on PSM levels, which will lead directly to results on advisement quality provided to students.
Hypothesis 1: Management will have a significant impact on PSM, which will impact the Advisement Quality and individual receives.

\section{Management PSM Performance (Advisement Quality)}

The study will consist of a series of interviews with advisors and their supervisors. The study will consist of 6 supervisors and 12 advisors. The advisors will be asked about their history, motivations, and advisement styles. The supervisors will be asked questions to determine their motivations and outlook on the advisement process. In addition to these interviews student interviews of their experiences with those advisors, and observation of the advisors behavior will all be used to gain an understanding of the advisors approach to advisement as well as their level of PSM. Through those interviews data will be compiled throughout the process to determine whether or not advisor behavior is impacted by supervisor activity.

\section{Interview Format}

Throughout the interview questions will be asked of each advisor/ supervisor. The questions are designed to determine different variables that may impact PSM and performance of Academic Advisors. Additionally as a result of the interviews each individual will be assigned an objective PSM rating from $0-5$, with 0 being a complete lacking of PSM and 5 being a high level of PSM. The evaluations will then be plotted on a graph to provide a graphical representation of the results. Advisors and Supervisors who score a 4 or a 5 on the PSM scale will be labeled as "High PSM". Pairs of $(4,4)$ or higher are desired and are hypothesized to yield the greatest service levels to students. The information collected and recorded will be used to determine what, if any, impacts the supervisors have on their subordinate academic advisors.

The questions have been meticulously examined to contribute very specific information to the study. Each question is prepared to address specific PSM and performance topics. Each reply is expected to provide insight into the thought process and value set of the interviewee. Replies will be documented and saved for later review and analysis. The replies from each interviewee will play a very important role in the determination of the PSM score that will be assigned to each advisor/ supervisor. The questions are listed below along with the rationale behind each question.

\section{Questions for Advisors}

\section{What does a typical advisement session look like for you?}

This question is designed to inquire into the process an advisor uses to assist students. Primarily if it is more bureaucratic and technical, or focused on counseling and students needs.

Is there anything you typically like to add at the end of an advisement session?

This question is designed to determine whether or not the advisor feels their role is to assist the student with as many elements of higher education as possible (student services, tutoring information, health and wellness, etc) or if they are more focused on the bureaucratic role of providing course information solely.

\section{Would you prefer students to make appointments or walk in?}

This is designed to see if the advisor has a student focused outlook, and whether or not the advisor is interested in assisting students when it is convenient for each individual student. 
Who is primarily responsible for providing general information about campus services at your institution?

This question is designed to determine if the advisor feels they are responsible for serving the student, or if they simply assist students in gathering course information only.

Do you strictly provide academic information, or do you provide additional info like careers, internships, etc?

This question is used to determine if the advisor is pro active in assisting students when they have the opportunity to engage them.

If the two conflict, which is most important; Institutional Policy or advancing the individual student's needs?

This question is designed to determine if the advisor feels they are an advocate for students, or more of a collector of information.

Do you feel your supervisor is more "hands on" or "hands off" as a management style?

Studies have shown management style impacts worker behavior. This question is going to be used to determine if it also has impacts on PSM by looking at differences in responses and PSM scale levels.

Do you feel that you and your supervisor share the same ideas about the goals of your position?

This question is going to be used to determine the communication levels between the advisor and the supervisor. After communication levels are determined replies will be compared to PSM levels to determine any results that may occur.

Do you feel your supervisor puts students in the forefront of their behavior as to make them a priority?

This question is designed to determine if the advisor is aware of the PSM levels of their supervisor. If the supervisor has high PSM levels and the advisor answers in such a way as to indicate that the supervisor does not, it may be an indication of the lack of clear expression of goals and institutional values.

\section{Questions for Managers/Supervisors}

How should the institution inform students about academic/ personal development and assistance programs that the University offers?

This question is designed to determine the supervisor's opinion on the role an advisor plays in the academic process. If they desire advisors to be closed off and narrowly focused they will reply different offices and name them, if they desire advisors to be outgoing and versatile and serve in multiple roles they would reply "everyone" or explain diversity of services within offices.

\section{How do you encourage your advisors to interact with students?}

This is intended to understand the manager's desired interaction of the student/advisor relationship.

What do you think is the most important role of an Academic Advisor?

This is designed to determine if the manager feels that the basic duties are most important, or if adapting and serving students should be at the forefront.

In your role, how do you feel you serve the students?

This is designed to determine what level of PSM the manager has.
Assuming that an Academic Advisor provided accurate course information to a student, if the student complained that they had a personality conflict with the advisor how would you handle the situation (with student and advisor, both, please explain)?

This question is intended to determine if the manager feels that the advisor should adjust to meet student expectations and needs, or if fulfilling the basic advisement procedures is sufficient.

If the two conflict, which is most important; Institutional Policy or advancing the individual student's needs?

This question is designed to determine if the advisor feels they are an advocate for students, or more of a collector of information.

In what way do you think advisors best assist students?

This question is designed to determine if the manager feels advisors are primarily bureaucratic or if they are more student focused?

Should advisors provide information to students and answer questions that are unrelated to academics?

This question is inspired by the Walsch article that explains advisors must have multiple roles, one of which as a counselor, if they are to adequately assist the students in addressing their needs. Answers to this question will indicate if the manager is primary focused on coursework, or the overall student transformation and development.

\section{PSM scoring}

The PSM scoring has been created based on researching other PSM models, and through the development of the concept of how PSM should exist in Higher Education professionals. The low/moderate category for PSM are scores 0-3. A PSM score of 0 is a complete lacking of PSM. These individuals have no desire to help students and little or no desire to complete any task. These individuals are obviously the least preferred individual to be working in a public service job. The next score is 1 ; this is a very low level of PSM. These individuals do very little to help students. Students are not the focus of their work, and there is very little desire to complete tasks.

A score of a 2 is also a low level of PSM. Similar to a 1 there is little desire to help students. The student is not the focus of the individuals work and they are more focused on the bureaucratic roles they have been assigned. They complete their tasks and will help students as a result of transactional activities when they can without giving any extra service effort. These types of individuals may meet every goal on paper of an educational professional, and they may even follow the rules quite accurately. However, their motivation to help students is lacking and as a result students are not served to the full potential.

A score of a 3 is a moderate level of PSM. The student is the focus of the individuals work and they assist student regularly. They complete their tasks and help students eagerly in the area that they are employed. Additionally these advisors feel they are constrained in their own role and often refer students to other areas instead of trying to assist the student in any way they can. These individuals help students, but there is more opportunities to serve and they are failing to act that way.

A PSM score of a 4 is a high level of PSM. The student is held as very important in the individuals work. They are concerned with task completion and serving students. The individual will go out of their way to help students. The student is held as more important that bureaucratic responsibilities, but rules apply and will be followed. The next step is a 5 , and it is a very high level of PSM. The student is still the focus of the 
individuals work. The individual knows and understands they are here to serve students. Their number one responsibility is student success which is more important than bureaucratic constraints, and different than a 4 rules may be bent or overstepped to help students.

The scoring system is simply use to differentiate differing levels of PSM in Higher Education professionals. It has not been studied to be scientifically accurate, but should be efficient at differentiating motivation levels across different individuals. Since includes specific traits held to be important in PSM in Higher Education, it should be consistent and reliable when separating traits among the individuals being interviewed and observed.

\section{Framework for evaluation}

As each advisor and supervisor are evaluated through the interviews their PSM score will be recorded. It will then be combined and paired with the appropriate supervisor. Each pair will then be evaluated on how they interact, and observations will be made as to the impacts the supervisor has on the advisor. Additionally, any management approach/technique that is observed to impact the performance of the advisor will be noted, as well as any unique interaction between supervisor and advisor. The interactions and relationships are expected to influence advisor PSM and as a result may influence performance and student service.

\section{Interviews}

The interviews were conducted in the supervisor/advisors offices over a 2 week span. The interviews are broken down into "Teams". Each Team consists of one supervisor, and two advisors (both supervised by the same advisor). They were asked a series of questions varying in nature from their management style, how they perceived work ethic, service motivation, and general service questions. The responses were unique to each advisor, but had some generalizable underlying themes.

\section{Team 1}

Each advisor/supervisor pair were ranked individually and their scores were combined to determine their location on the chart. To explain and compare and contrast each individual each interviewee will be assigned a generic name. The first supervisor, Spv1, oversees the work of a team of academic advisors. She is primarily interested in her staff and appears often times to have goals that are not student focused. When asked about course policy she explained that "faculty want things to be done a certain way and that's how we do it." This was very different than a student centered approach that may have been given by a supervisor with high levels of PSM. Her conversations often drift away from student needs and shift to her ideas and what she thought would be best for individual departments and she discussed student needs seldom if at all. For these reasons she was assigned 2 on the PSM scale.

The advisors she oversees are Advla, and Adv1b. Advla advises non first time entering declared major students. He has been an advisor for over 10 years and is knowledgeable about the content of the curriculum he advises. His general communication is short and abrupt. When asked about his recommendations for courses that students should take he explained that "he enrolls them in classes he wants them to take because he knows what is best for them". Continued conversation about this led to the observation that he does not take the initiative to understand the student's goals or their needs and desires. He is very transactional and rushes students through the process. Throughout the observation of his advisement practices several students were observed crying and unhappy with their experiences with him, even though they were not given bad news about their grades or degree. His understanding of the curriculum appears to lead him to be more instructing instead inquiring about students goals. Through the interview and observation it appears that students are not the driving motivation behind Advla's work. He also lacked the desire to complete the basic tasks required to advise the students. For this reason he was assigned a 1 on the PSM scale (Table 1).

Adv $1 \mathrm{~b}$ also advises non first time entering declared major students. He has been an advisor for 8 years. Throughout my conversation with him he also did not speak of students as if they were the motivating factor behind his work. He was very transactional, but unlike Advla he was receptive and willing to complete some of the tasks required of an academic advisor. It appears that he helps students as a result of completing those tasks, but does not speak about students in a service motivated fashion. He is very transactional and is not willing to vary from his advisement structure to help students. He completes his pre determined advisement plan and concludes the advisement session to move to the next student. (Worth noting is that he is not overbooked and has several times when he is not advising students. The practice of rushing students is not due to having students waiting). His conduct and lack of explanation to students has resulted in assigning him a 2 on the PSM scale. This is because students are helped throughout the process, but only as a side effect of the transactional nature that drives him to complete the task. Students are never described as a motivating factor and PSM seems to be lacking if present at all.

\section{Team 2}

Spv2 supervises advisors who work with students who are nontraditional or high risk students. He is very student focused in his approach to higher education. He feels he is able to serve students by giving his advisors the training and equipment they need to be successful. He explains that students should be first in the activity of higher education professionals. He feels to serve students they should facilitate the meeting of student needs in the format desired by students. He feels that the staff should be informed on a variety of issues and be prepared to answer questions outside their specified area of service. At the very least he feels that all employees should know exactly who to refer a student to for any need they may have. He specifically addressed the importance of "listening to students needs, and then addressing those needs accordingly". Adv2a provided valuable information to this research. She was very pro student and it was clearly observable student success was the motivating factor behind her work. She explains that she goes above and beyond for her students, and will break institutional policy at times if needed to help a student. A few things differentiated her from advisors who would rank a 4 or 5 on the PSM scale. First, she explained that it was the role of others offices to complete tasks that universally advisors could handle. She appeared to behave as if she is closely confined and didn't want to overstep boundaries into other areas that might have individuals assigned to handle them. Secondly, although she explained student needs are the most important she acted on the contrary if that need required her to answer questions that she felt should be answered by someone else even if she found herself capable of answering it. For these reasons she has been assigned as a

\begin{tabular}{|c|c|c|c|}
\hline & $\begin{array}{c}\text { Hands off } \\
\text { Supervisor }\end{array}$ & $\begin{array}{c}\text { Hands on } \\
\text { Supervisor }\end{array}$ & Total \\
\hline High PSM & 4 & 1 & 5 \\
\hline Low/Med PSM & 1 & 6 & 7 \\
\hline Total & 5 & 7 & 12 \\
\hline
\end{tabular}

* Low/Med is a score of 3 and below

Table 1: PSM levels at various grades. 
3 on the PSM scale. Adv2a explains that the supervisor is very "hands on" and guides her activity heavily. Her supervisor labeled himself "hands off" which is contradictory to the reporting of other advisors supervised by the same person as they label him as "hands off". This is interesting because her Adv2a's labeling of her supervisor as "hands on" might be related to her obvious feeling that she is not empowered to branch out and serve students even though her supervisor explained his concern that every advisor should be prepared to answer most questions even ones outside their designated area of service. Adv2b is an academic advisor who has advised for about 6 years. She is a very pro student advisor and explains she takes care to listen to the students wants and needs and gives them appropriate advice and assistance. She feels it is the role of the university to prepare brochures and materials to inform students of important material. She feels her supervisor is "hands off" and he lets her "do her thing!" She additionally seems to feel empowered to make her own decisions and at times will trek into other department's areas of focus and answer those questions. She does observe rules, but navigates around them and to help students. As a result she has been assigned a 4 on the PSM scale for her tendency to put students first and keep them as a priority in her day to day activities.

\section{Team 3}

The third supervisor, Spv3, is a supervisor over advisors who advise non first time entering students. This supervisor is very pro student and she is very similar in approach to Spv2, and her advisors are similar as well in practice and ideology. Additionally, the advisors, Adv 3 a\&b, also had different perceptions of their supervisors. Adv3a feels that the supervisor is "hands off", and like the advisors from group 2 also feels that he is empowered to work as he sees best to serve students. Adv3b feels that the supervisor is "hands on" and he feels that he is unable to make individualized decisions, and does not venture outside the specified area he has been assigned. Another interesting finding is how each advisor perceived whether or not their supervisor put students first in the forefront of their work. Both advisors felt that students were not the driving motivating factor for all of their supervisor's decisions and actions. In both of the supervisor-advisor relationships a similar trend was present; advisors who felt their supervisors were "hands on" were less empowered to make their own decisions and to provide information to students on their own. Also both advisors did not have students in the forefront of their actions.

\section{Team 4}

Spv4 supervises advisors who interact with first time freshmen students. He has been supervising in similar roles for nearly thirty years. Through the interview process he explained his outlook on advisement and supervision. His explanation suggests his focus is student centered and he holds student success as an extremely high priority. He explains that as a manager "rules are important, but he expects his advisors to do everything they can to help students." As an institution he wants to have a strong "student centered culture" which fosters student success. He wants his advisors to answer questions in any area that they feel adequately informed to help students. He wants them to be able to answer questions outside their area of employment so they can better assist students. For his student centered approach, and feelings that rules are important, Spv4 has been assigned as a 4 on the PSM scale.

The advisors that Spv4 supervises are Adv4a and b. Both of these advisors are very student focused. They explained that they both go above and beyond to benefit students. One interesting finding that echoes other supervisor-advisor relationship is the responses to the management styles and approaches to advisement. Adv4a said that she perceived the supervisor to be "hands off". She also responded that she would go outside her area of employment to answer questions students may have. Adv4b also feels that her supervisor is "hands off", but still at times would rather refer students to other departments. However, this is consistent with the outlook of her supervisor who recommends they only provide information they are confident to provide, and this advisor is relatively new in her current position and office. Different from other supervisor-advisor relationship is the fact that both of these advisors feel their supervisor puts students in the forefront of their actions. Both advisors felt that their supervisor had the same goals they did for their position and noted that those goals have been clearly expressed to them. This is particularly interesting as it was the first time this condition existed in both advisors, and this pair of advisors both scored a 4 or higher on the PSM scale.

\section{Team 5}

Spv5 is somewhat different that the other supervisors. She is a very passionate person and the words she uses to describe the role of academic advisors includes "compassionate, listen, encourage, etc". She is new to being a supervisor and has only supervised in similar roles for a little over a year. She feels strongly that the role of the advisor is not simply transactional; instead it should be encouraging and uplifting. In her role she feels she helps students by openly communicating and advocating for her advisors in every setting. She feels that if the advisors are better equipped and empowered then they will be able to better meet the needs of the students. She also feels that it is important to defend advisors and believe in their work. She feels that rules need to be followed, but can be overruled in the gray areas. Her passion for service and willingness to openly communicate with advisors shows she has high levels of PSM. She does follow policy and understands its role in the organization. These two observations place her in the PSM 4 level as determined by our PSM scale.

Adv5 $\mathrm{a}$ and $\mathrm{b}$ appear to be one of the better advisor combinations to compare and contrast for the study. Adv5a is a good advisor, and is observed as genuinely caring about student success. She discusses the right information with students, and provides them with appropriate resources when she is asked for input. However there are a few concerns that have resulted with her placement as a 3 on the PSM scale. First, when asked who should provide information about general college services she replied another office besides her own. This is concerning for two reasons. First, her supervisor clearly expressed when being interviewed that it is important for advisors to provide this type of information to their students instead of referring them around campus. Second, other offices on campus, including the ones she referred students to, feel that it is Adv5a's offices responsibility to answer such questions and they refer students to that office regularly. Additionally, Adv5a feels that students should make appointments to see her. This is different from what the supervisor preferred and what other similar advisors feel. Some advisors explain that they are always available to help students and the door is always open. Adv5b answers were nearly perfect across the board. This advisor is passionate for service and her answers reflected her ideals in regards to students. She explained that appointments are not required for her as she has an "open door policy" and will see a student whenever she can. When asked who should help students with general questions she replied that offices should "send them [students] her way". She also stated that she often openly disregards policy if it is against the best interests of the students. The one question that reflected her public service motivation the most was the question regarding "who is responsible for assisting students with academic and personal goals". She replied to this question "everyone". 
For her extreme dedication to students and her willingness to override policy in that pursuit she is given a 5 on the PSM scale.

An interesting finding that occurred when asked about Adv5a/b’s supervisor may provide additional insight into the supervisor-advisor relationship, and further explain some of their answers. Adv5a explained that her supervisor is very hands on, and that the supervisor takes an overly active role in how decisions and situations are handled in the office. Additionally she explains that her supervisor is more focused on policy than on individual students needs. This is directly the opposite from the interview with Adv5b who states that the same supervisor is "hands off", and places students in the forefront of her behavior and work. The same advisor is perceived in very different ways and at the same time the PSM of the advisors also varied greatly. Adv5a was given a 3 on the PSM scale, and Adv5b was given a 5.

\section{Team 6}

The sixth advisement pair interviewed also provided very different ideas of academic advisement and thoughts on the process. Adv6a is a very transactional advisor. She completes the tasks, and advises strictly by policy. She informs students of the basic information, but that is it. She openly explains that some students are better than others and some simply will not succeed. As a result she seems to be bitter towards advisement as sometimes she has to work with the students who are less likely to make it and she feels that is a waste of time. When asked "who should provide general information about services available on campus" she replied" pshhh, out of my pay grade I don't think about that". It is apparent she feels that she has a small task to attend to and that is the only thing she is concerned with. Since she does complete tasks, and helps students as a result, but feels confined and does not reach out to help students as much as possible she has been assigned a 3 on the PSM scale. When asked about her supervisor she explained that she feels she is "hands on" as a general rule. Adv6a explains that her supervisor does not always put students first, and that sometimes bureaucratic tasks or rules are more important.

Her counterpart, Adv6b has a very different advisement style and observations of the supervisor. She places students and student needs at the forefront of her decision making. She feels that other offices may be responsible for certain areas of information disbursement, but she still feels she should be adequately informed so she can answer any questions that come her way. She asks about personal goals, career goals, and often ventures into other areas besides her specific assigned responsibility area. She finds ways to navigate around institutional policy so she can help students and put their interests first in her conduct. Due to her pro student mentality and rule observation she has been given a 4 on the PSM scale. When Adv6b was asked about her supervisor she explained that the supervisor was very pro student and put student's needs in the forefront of her behavior. She also explained the supervisor was a role model and served as an example of how to help students.

Spv6 feels advisors are there to help students understand the process and guide them throughout their journey. She feels that advisors should be well versed in other areas of the college so they can inform students on a wide array of issues that may be impacting them. She wants her advisors to be outgoing and to be available to help and assist students. She feels she serves students by guiding advisors to be better in their efforts, and to have the means necessary to do their jobs effectively. Due to her ability to go above and beyond, bending of rules, and her motivations to help students and assist her employees she is given a 5 on the PSM scale.

\section{Findings}

There are three fundamental findings to the study.

1. Advisor PSM is directly correlated to Supervisor PSM when the advisors are aware of the Supervisors motivation level.

2. Advisors that were shown to have higher levels of PSM had supervisors who held students as a High priority and adequately conveyed those priorities to the advisors.

3. Advisors who are unaware of the supervisors PSM will perform independently of their supervisor's level of PSM.

4. When the supervisor failed to adequately communicate the goals and the priorities that students hold in the work place, advisors behaved uninfluenced by the Supervisors PSM levels. In every sample in the study, the PSM levels of these advisors were much lower than those with supervisors who communicated the importance of helping students.

5. When the supervisors clearly communicated the goals and values of the organization and what that meant in terms of student service, advisors served students better. An important note is that an advisor can efficiently carry out the task of transactionally advising students without being high in PSM levels.

6. Advisors who have supervisors who they perceive as "hands off" will be more likely to perform at a higher level of service than those with "hands on" supervisors.

7. Of the advisors interviewed, 5 had high PSM scores while the remaining 7 had mid to low scores. Of those advisors who scored high on the PSM scale, $80 \%$ reported having supervisors who were "hands off" and of the advisors who scored low-mid on the PSM scale $86 \%$ reported to have supervisors who were "hands on". Through the study it has been observed that supervisors who follow a more "hands off" approach empower their employees to take a more active role in serving students. Through the interviews the reason this has occurred appears to be due to the "silo effect". Advisors who have supervisors who were "hands on" felt trapped in their own role, and never ventured outside their specified area of employment. This resulted in advisement practices that were purely academically centered. Most scholars would suggest that the university experience is preparing students for the "real world" and as a result purely academic advice is not contributing to a successful transition into the next step of student development. The other approach would be advisement staff who felt comfortable and willing venturing into other areas of service to contribute and help students. This can include admissions, career services, testing, financial aid, job placement, etc. Advisors who took an active role in gathering this information to help students, even though it was not their specified job, always scored higher on the PSM scale and provided better service to students (Figure 1).

\section{Conclusions}

\section{Hypothesis 1}

Management will have a significant impact on PSM, which will impact the Advisement Quality an individual receives.

\section{Management PSM Performance (Advisement Quality)}

Hypothesis one has been upheld through the three fundamental findings of the study. Through the study several activities have been identified that seem to increase PSM, decrease PSM, and some that leave subordinates confused and out of line with goals and objectives. 


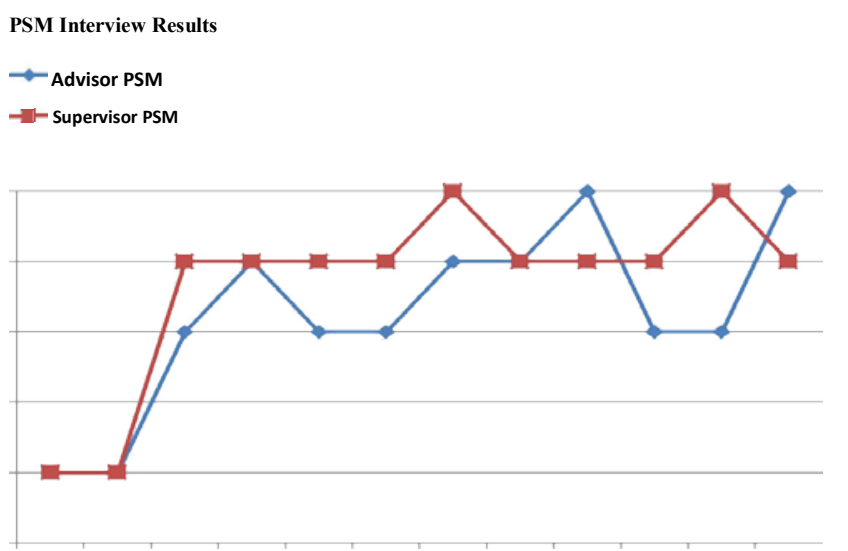

Figure 1: Shows the combination of Supervisor PSM and Advisor PSM for the advisor/supervisor pairs in the study. There are several types of relationships in the study. Of the six advisors in the study five had PSM ratings of 4 or higher and one had a rating of 2 .

Activity that should be avoided is being vague and ambiguous in communicating with employees. This includes both failure to communicate expected employee goals and activity, and failing to communicate the goals of the supervisor. Additionally a "hands on" approach to managing employees creates environments where employees are less motivated to serve the public.

Conduct that was conducive to highly motivated employees seemed to be similar across departments and locations. The positive activities included providing an open "hands off" environment for employees to serve the public. This approach resulted in employees who felt free to take extra initiative and go the extra mile to serve students. Also the successful supervisors who had high PSM advisors were open in their communication about their activities and their motivation to help students. They also clearly defined the advisors role in serving both students and the institution which allowed the advisors to feel as if they are contributing and feel motivated to help students.

This study is relevant to the study of PSM in the Public Administration community because it indicates that supervisor behavior can have a direct impact on subordinate PSM. Through their actions, supervisors they will have the opportunity to harness and expand the motivation levels of their subordinates, which has a direct impact on the performance levels of those subordinates (either positive or negative according to their actions). This is important for future studies in the Public Administration community as more traits and activities can be identified that can contribute to the increase in PSM of subordinates and as a result the opportunity to increase performance as a byproduct is also increased.

\section{References}

1. James P, Wise L (1990) The Motivational Basis of Public Service. Public Administrative Review 50: 367-373.

2. James P (1996) Measuring Public Service Motivation: An Assessment of Construct Reliability and Validity. Journal of Public Administration Research and Theory 6: 5-22.

3. David C, Pandey S (2009) Public Service Motivation Measurement Administration and Society 39: 547-568.

4. Philip C (1997) Public Service Motivation: Building Emperical Evidence of Incidence and Effect. Journal of Public Administration Research and Review 7: 499-518.

5. Gregory M (2006) A Motive to Serve. Public Personnel Management 35: 33-48

6. Leonard B (2009) Why do Public Employees Desire Intrinsic Nonmonetary Rewards. Public Personel Management 38: 15-37.

7. Craig B, Sundquist E (2009) Effective Public Service. The American Review of Public Administration.

8. James P, Brudney J, Coursey D, Littlepage L (2008) What Drives Morally Committed Citizens? A study of Antecedents of PSM. Public Administration Review 68: 445-458.

9. Lewis GB, Alonso P (1999) Public Service Motivation and Job Performance. Orlando.

10. Brewer GA, Selden SC (1998) Whistle Blowers in the Federal Civil Service. Journal of Public Administration Review and Theory 8: 418-439.

11. David M, Pandey S (2007) The Role or Organizations in Fostering Public Service Motivation. Public Administration Review: 40-53.

12. Bright, Leonard (2005) What do They Want? Public Employees with High Levels of PSM. Review of Public Personal Administration.

13. Georgellis, Yannis, Vurain Tabvuma. Does Service Motivation Adapt? KYKLOS 63.

14. Laurie P, Lavigna B (2010) Transformational Leaderhip and Public Service Motivation. Public Administration Review 70: 710-718.

15. Sung P, Rainey H (2008) Leadership and PSM in US Federal Agencies. International Public Management Journal 11: 109-142.

16. Grant, Adam, John Sumanth (2009) Mission Possible? The Performance of Prosocially Motivated Employees Demand of Managers. Journal of Applied Psychology 94:927-944

17. Wimbush, James (1994) Towards an Understanding of Ethical Climate. Journal of Business 94:637-647.

18. Bruce A, Gardner W (2005) Authentic Leadership Development. Leadership Quarterly 10:315-338.

19. Kellie B (2003) Advice for Academic Advisors. Chronicle of Higher Education.

20. David M, Pandey S, Wright B (2009) Pulling the Levers: Leadership, Public Service Motivation and Mission Valence. Bloomington. 